\title{
ANALYTICAL INVESTIGATION OF MR DAMPER FOR VIBRATION CONTROL: A REVIEW
}

\author{
K. Sumanth Ratna ${ }^{\text {a }}$, C. Daniel ${ }^{\text {b,c,*}}$, Anshika Ram ${ }^{\text {b }}$, B. Siva Kumar Yadav ${ }^{\text {b }}$, G. Hemalatha ${ }^{\text {b }}$ \\ ${ }^{a}$ Department of Mechanical Engineering, Karunya Institute of Technology and Sciences, Coimbatore, India \\ ${ }^{\mathrm{b}}$ Department of Civil Engineering, Karunya Institute of Technology and Sciences, Coimbatore, India \\ $\mathrm{c}^{*}$ Department of Civil Engineering, Mohamed Sathak A J College of Engineering, Chennai, India
}

Received: 05.02.2021 / Accepted: 17.03.2021 / Revised: 20.04.2021 / Available online: 31.05.2021

DOI: 10.2478/jaes-2021-0007

KEYWORDS: Magnetorheological damper, analytical, self-power, vibration control.

\begin{abstract}
:
In this paper, a vibration control system with magnetorheological (MR) damper investigation is reviewed. At first a MR damper is investigated analytically using various finite element method software and the performance is investigated using experimental. The MR Dampers are designed and modelled for a scaled down setup. The application is in seismic resistance of buildings, automobile, physical and biological. Finally, the damper is investigated using various technique and methods used to study the performance is reviewed. This device reduces the vibration in both active and semi active control system effectively.
\end{abstract}

\section{INTRODUCTION}

Now a days, the magnetorheological dampers are used in to the various vibration control applications in real time practices and several projects are functioning in MR dampers. To reduce the dynamic vibration forces developed in the structural elements, to increase their efficiency of the life MR Damper is used. The MR damper is a semi active vibration control device in which by using input electric current the viscosity of fluid is regulated and damping force is produced. The MR dampers are used in various applications in the practices of civil structures, automobile vehicle and medical. Rashid, M. M et al., 2015 briefly classified into three control system, which is active, passive and semi- active. Passive dampers have many limitations; however, these ones are the selected by the designers. MR dampers come under the type of semi-active suspension system. For semi-active control systems using a magnetic field and MR fluid, the researchers showed substantial improvement in design optimization. Finite element methods, electromagnetic magnetic field analysis, and MR flow computational fluid analysis were used to get the optimum value for parameters for the device. The dampers are manufactured and experimentally investigated using various configuration (Parlak, $\mathrm{Z}$ et al., 2012).

A standard valve design in the MR damper impacts the magnetic forms impact the efficiency of the MR parallel vent drives was evaluated. The findings show that the simulation values on the Finite-Element system are very close to calculated values and durability, as well as to specific design parameters and materials, resulting from the MR integrated damper configuration (Yang, B et al., 2010). The rheology of MR fluids established as a Bingham nonlinear hysteretic model. The parameters are calculated using non-linear method associated with the current supplied to the magnetic coil. The simulations are determined, according to the mechanical framework by ANSYS (Zhang, Z. X \& Huang, F. L. 2013).

The ANSYS simulation examined the vibration damping harmonically (Yinong, L. W. Z. L. L., \& Yong, H. 2007). ANSYS FEM analysed the propagation of MR fluid for different structural models and the dual magnetic mechanism (Wu, J., \& Wang, H. F. 2008). The magnetic circuit is designed for MR damper, its efficiency was achieved (Yu et al., 2007). The composite MR damper for the semi active control system with power consumption control system, safety and efficiency of Damper. The designed damper provides passive and semiactive improvements in mechanical layout (Wenliang 2004). The electromagnetic field in MR Dampers spreading the damping forces (Wenkui, L et al., 2013). The piston in MR damper is analysed in view of electromagnetic field, the designs were light weight, compact and improvement in magnetic field distribution. It can be analysed in Ansys too (Yang et al., 2013, ZHANG et al., 2004, Khan et al., 2012).

The 2-D axi-symmetric MR damper finite element model and investigated. The performance of a single coil with filleted piston ends is better for the same scale than other designs (WANG et al., 2005). The MR Damper relationship between mechanical designs, magnetic field and damping force, a mathematical model is developed (Sung et al., 2011). The dual coil piston MR damper is simulated using Ansys software (LI et al., 2009). The Solid117 component in Ansys APDL analysed

\footnotetext{
* Corresponding author: C. Daniel, Assistant Professor, Department of Civil Engineering, Mohamed Sathak A J College of
} Engineering, Chennai, Tamil Nadu, India, e-mail: danielckarunya@gmail.com. 
using non-linear magnetic properties of the fluid and the magnetic core material was analysed (ZHU, S et al., 2015). The magnetic circuit simulation model is optimized and magnetic flux density of MR Damper is analysed (GONG et al., 2010). The mathematical modelling of MR Damper is performed (Ferdaus et al., 2014).

In the critical review, the application of MR Damper for various fields was studied and mechanical parameters were studied for all applications.

\section{ANALYTICAL INVESTIGATION}

RD-8041 MR Damper is used for resist vibration occurs un automobiles. The damper configuration is depicted in figure 1 . The performance test was carried out (Hu et al., 2015). The physical properties and damping mechanisms in mechanical systems is modelled using ANSYS. In order to determine the manufacturing costs of this parts of MR Damper is specified. This type of damper is used in automobile application as shown in figure 2 (Ferdaus et al., 2014).

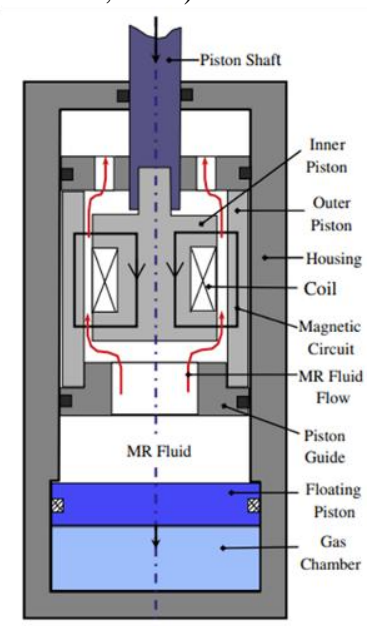

Figure 1. MR damper configuration (Hu et al., 2015)

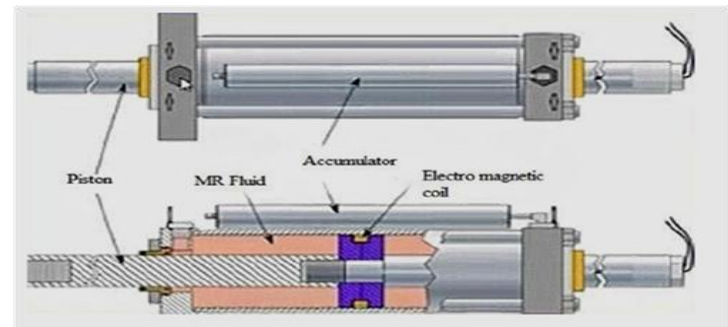

Figure 2. Parts of MR damper for Automobile application (Ferdaus et al., 2014)

The self-powered MR damper for vibration control is designed, using EMI technique the frequency and amplitude is determined. The fluid stress, viscosity and sedimentation parameters also incorporated in the design. The self-powered MR Damper diagram is depicted in figure 3 (Ferdaus et al. 2014).

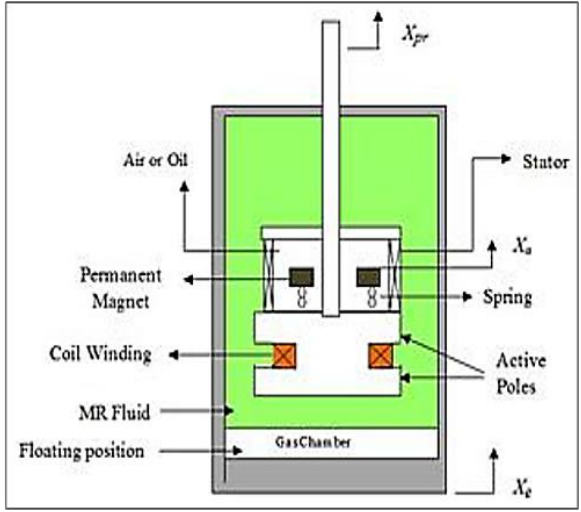

Figure 3. Schematic diagram of self-powered MR damper (Ferdaus et al. 2014)

There scalability and magnetic functionality of MR dampers is discussed in terms of magnetic saturation is extended to provide a high performance (Hemanth, $\mathrm{K}$ et al., 2014). The comparison of 2-D Axisymmetric and 3-D MR Damper models were simulated (Gohil et al., 2013). The Magnetic Saturation Model in ANSYS was studied (Lee et al., 2013). A simulated MR Damper with Bingham MR fluid model is configured and evaluated using an algorithm. The cylindrical MR Damper designed for medium-sized vehicle. The optimization for electronic circuit system were designed. The initial and optimum damping force with various tie interval is studied (Zhimin et al. 2010). The magnetic circuit optimization and FEM research is also analysed using ANSYS. The design and parts are shown in figure 4 (Gurubasavaraju et al., 2017)

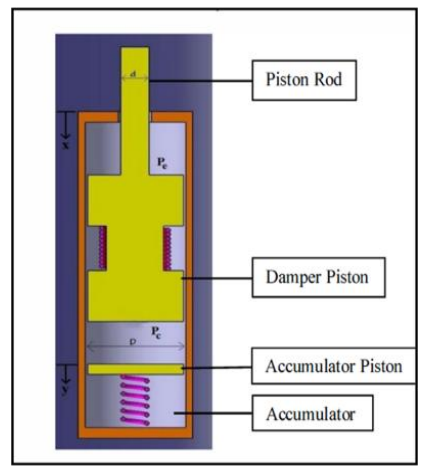

Figure 4. Accumulator design of MR damper

A spinning magnetorheological damper has been developed and tested for vehicle suspension systems. The torques reached 1.5 A, of $475 \mathrm{~N} \cdot \mathrm{m}$ and demonstrated errors of under $5 \%$ over the proposed built MR damper. The cross section of the MR Damper is depicted in figure 5 (Zhu et al., 2015).

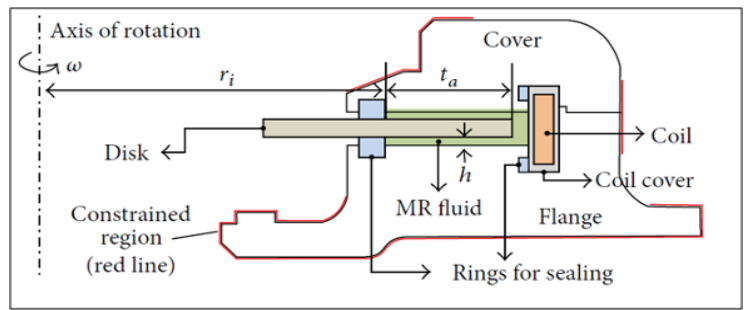

Figure 5. Cross-section of the rotary MR damper (Zhu et al., 2015) 
The optimization of magnetic flow rate and fluid flow differences are minimised. Fluid flow frequency, electromagnetic coil size and input current in design variables are considered. In Finite Element Analysis (ANSYS) achieved the highest Magnet Flow Rate, the best design parameter configuration is specified as proposed (Mangal et al., 2014). The dissipated energy in MR damper systems is important both dynamics and energy recycling from mechanical movements with compact mechanisms for generating electricity. The analytical modelling of self-powered MR Damper is modelled and investigated (Gurubasavaraju et al., 2018). A twodimensional comparative analysis of MR damper is simulated. The schematic drawing is shown in figure 6 (Sternberg et al., 2014).

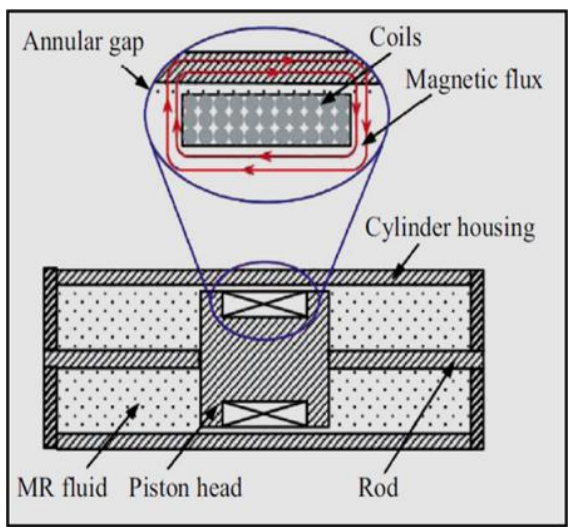

Figure 6. Schematic drawing of shear-value modal MR (Sternberg et al., 2014)

The MR damper with self-powered is developed in the principle of electromagnetic induction (EMI). There were a permanent magnet, coil and energy storage section. The proposed MR damper force generate $750 \mathrm{~N}$ with $0.6 \mathrm{~A}$ current $(\mathrm{Hu}$ et al., 2016)

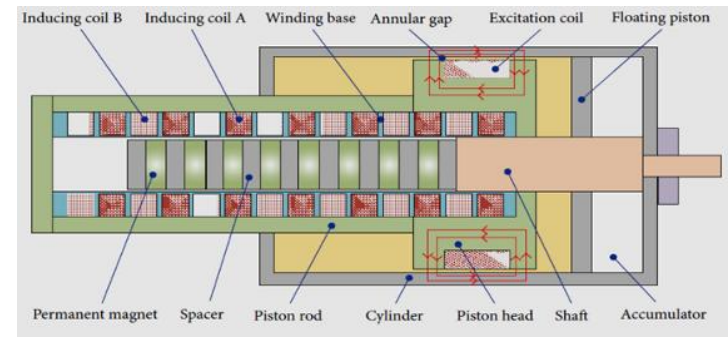

Figure 7. Schematic diagram of MR damper with energy harvesting ability (Hu et al., 2016)

The finite element analysis was carried out in Ansys software carries out for 3 similar models, it is fabricated and tested in vibration control laboratory. A These findings will help car designers produce more effective and robust MR dampers and forecast their damping force features (Cai et al., 2002). Experimental and computational approaches were developed for a double-tube MR damper for structural vibration control (Zhang et al., 2006). Multi-physics computational models are used to measure the dampers movement in high rise buildings. The relationship of the MR fluids behaviour, and structural assessments is tested by finite-element models. Magnetic field and dynamic existence of the fluid in system are defined by Stokes equations (Nguyen et al., 2009).

The first order optimization approach using FEM software, restricted optimization algorithm is developed. The comparison of control performance, including vertical speed, rotation of suspension and energy consumption is examined. The schematic diagram and experimental setup is depicted in figure 8 (Peng et al. 2019).

\section{DISCUSSION AND CONCLUSION}

The existing MR Damper has a broad advantage in many fields and many designs are investigated analytically and experimentally. The electrical energy activates the MR Damper, which produce the magnetic field in the MR Damper to active the MR fluid. The application of MR damper is in automobile, buildings, biology, physics and electrical fields. Through this review, the investigation is not limited to analytical and experimental, many numerical investigation applications are not only limited to this fields, this can be applied in many fields to reduce the vibration of the system. The self-power damper, selfsensing damper and more advancement in design and modelling also made to be standard in future.

\section{References}

Cai, C., Zheng, H., Khan, M. S., \& Hung, K. C.,2002. Modeling of material damping properties in ANSYS. In CADFEM Users' Meeting \& ANSYS Conference, pp. 9-11.

Ferdaus, M.M., Rashid, M.M., Bhuiyan, M.M.I. and Muthalif, A.G.B.A., 2014. Design and Performance Evaluation of a SelfControlled Magneto-Rheological Damper. International Journal of Robotics and Mechatronics, 1(2), pp.74-80.

Ferdaus, M.M., Rashid, M.M., Hasan, M.H. and Rahman, M.A., 2014. Optimal design of Magneto-Rheological damper comparing different configurations by finite element analysis. Journal of mechanical science and technology, 28(9), pp.3667-3677.

Gohil, G.S. and Srivastava, R., 2013, April. Mechatronic design of Magneto-rheological damper for automobiles. In 2013 Students Conference on Engineering and Systems (SCES) (pp. 1-6). IEEE.

GONG, Z., MA, P. and CHEN, A.M., 2010. Multi-Objective Optimization of Magnetorheological Damper Based on the FEM [J]. Mechanical \& Electrical Engineering Technology,

Gurubasavaraju, T.M., Kumar, H. and Arun, M., 2017. Optimisation of monotube magnetorheological damper under shear mode. Journal of the Brazilian Society of Mechanical Sciences and Engineering, 39(6), pp.2225-2240.

Gurubasavaraju, T.M., Kumar, H. and Mahalingam, A., 2018. An approach for characterizing twin-tube shear-mode magnetorheological damper through coupled FE and CFD analysis. Journal of the Brazilian Society of Mechanical Sciences and Engineering, 40(3), pp.1-14.

Hemanth, K., Ganesha, A., Kumar, H. and Gangadharan, K.V., 2014. Analysis of MR damper based on finite element approach. In Applied Mechanics and Materials (Vol. 592, pp. 2006-2010). Trans Tech Publications Ltd. 
Hu, G., Lu, Y., Sun, S. and Li, W., 2016. Performance analysis of a magnetorheological damper with energy harvesting ability. Shock and Vibration, 2016.

Hu, G., Xie, Z. and Li, W., 2015, June. Optimal design of a double coil magnetorheological fluid damper with various piston profiles. In World congress on structural and multidisciplinary optimisation, pp. 2-7.

Khan, M.S.A., Suresh, A. and Ramaiah, N.S., 2012. Analysis of magnetorheological fluid damper with various piston profiles. International Journal of Engineering and Advanced Technology, 2(2), pp.77-83.

Lee, J.H., Han, C., Ahn, D., Lee, J.K., Park, S.H. and Park, S., 2013. Design and performance evaluation of a rotary magnetorheological damper for unmanned vehicle suspension systems. The Scientific World Journal.

Li, J.Q., Zang, X.Z. and Zhao, J., 2009. Magnetorheological Damper 3D Simulation with Finite Element Method. Journal of System Simulation.

Mangal, S.K., Kumar, A. and Chattopadhyay, K.D., 2014. Development of $\mathrm{Mr}$ damper modeling and its experimental validation. IUP Journal of Mechanical Engineering, 7(3), p.35.

Nguyen, Q.H., Choi, S.B. and Kim, K.S., 2009, February. Geometric optimal design of MR damper considering damping force, control energy and time constant. In Journal of Physics: Conference Series (Vol. 149, No. 1, p. 012076). IOP Publishing.

Parlak, Z., Engin, T. and Çallı, İ., 2012. Optimal design of MR damper via finite element analyses of fluid dynamic and magnetic field. Mechatronics, 22(6), pp.890-903.

Peng, Y.B., Zhang, Z.K., Yang, J.G. and Wang, L.H., 2019. Full-scale simulations of magnetorheological damper for implementation of semi-actively structural control. Journal of Mechanics, 35(4), pp.549-562.

Rashid, M.M., Ferdaus, M.M., Hasan, M.H. and Rahman, A., 2015. ANSYS finite element design of an energy saving magneto-rheological damper with improved dispersion stability. Journal of mechanical science and technology, 29(7), pp.2793-2802.

Sternberg, A., Zemp, R. and De La Llera, J.C., 2014. Multiphysics behavior of a magneto-rheological damper and experimental validation. Engineering Structures, 69, pp.194-205.

Sung, K. G., Choi, S. B., \& Park, M. K. (2011). Geometry optimization of magnetorheological damper for vehicle suspension via finite element method. Advanced Science Letters, 4(3), 805-809.

WANG, J., WANG, Q. and LI, Y., 2005. Finite element analysis of magnetorheological damper. In Electrorheological Fluids and Magnetorheological Suspensions (Ermr 2004) (pp. 722-727).

Wenkui, L., Fei, C. and Jinyuan, Z., 2013. Analysis of magnetorheological damper magnetic based on ANSYS. Modern Manufacturing Engineering, p.03.
Wenliang, W.J.W.Q.H., 2004. Research on The Finite Element Analysis of Electromagnetic Field and Structure of MagnetoRheological Dampers [J]. Journal of Ballistics.

WU, J. and WANG, H.F., 2008. Magnetic circuit optimum design of a magneto-rheological damper based on ANSYS [J]. Mechanical \& Electrical Engineering Magazine,

Yang, B., Luo, J. and Dong, L., 2010. Magnetic circuit FEM analysis and optimum design for MR damper. International Journal of Applied Electromagnetics and Mechanics, 33(1-2), pp.207-216.

Yang, L., Chen, S.Z., Zhang, B. and Feng, Z.Z., 2011. A rotary magnetorheological damper for a tracked vehicle. In Advanced Materials Research (Vol. 328, pp. 1135-1138). Trans Tech Publications Ltd.

Yinong, L.W.Z.L.L. and Yong, H., 2007. FEM Analysis of Magnetic Field of Piston-type MR Fluids Damper [J]. Transactions of the Chinese Society for Agricultural Machinery.

Yu, G.J., Du, C.B. and Sun, L.G., 2007. The design of a newstyle composite MR damper and magnetic circuit simulation analysis. Ji Xie She Ji Yu Yan Jiu (Machine Design and Research), 23(3), pp.113-117.

ZHANG, H.H., LIAO, C.R., CH EN, W.M. and HUANG, S.L., 2004. Magnetic design of MR damper and FEM a nalysis on saturation [J]. Journal of Functional Materials and Devices.

Zhang, H.H., Liao, C.R., Chen, W.M. and Huang, S.L., 2006. A magnetic design method of MR fluid dampers and FEM analysis on magnetic saturation. Journal of intelligent material systems and structures, 17(8-9), pp.813-818.

Zhang, Z.X. and Huang, F.L., 2013. A new magneticrheological damper nonlinear bingham hysteretic model and ANSYS implementation. In Applied Mechanics and Materials (Vol. 351, pp. 1146-1151). Trans Tech Publications Ltd.

Zhimin, H.Z.F., 2010. Property Analysis of Magnetorheological Damper Based on Finite Element Method Simulation [J]. Modern Scientific Instruments.

ZHU, S., WU, W. and LIU, B., 2015. Magnetic Circuit Improving Design and Simulation Analysis for MR Damper of Hole-type. Machine Tool \& Hydraulics, p.04.

Zhu, X., Wang, W., Yao, B., Cao, J. and Wang, Q., 2015, July. Analytical modeling and optimal design of a MR damper with power generation. In 2015 IEEE International Conference on Advanced Intelligent Mechatronics (AIM) (pp. 1531-1536). IEEE. 